University of Wollongong

Research Online

Australian Institute for Innovative Materials -

Papers

Australian Institute for Innovative Materials

$1-1-2017$

\title{
3D-Printed Conical Arrays of TiO2 Electrodes for Enhanced Photoelectrochemical Water Splitting
}

Chong Yong Lee

University of Wollongong, cylee@uow.edu.au

Adam Taylor

University of Wollongong, taylora@uow.edu.au

Stephen T. Beirne

University of Wollongong, sbeirne@uow.edu.au

Gordon G. Wallace

University of Wollongong, gwallace@uow.edu.au

Follow this and additional works at: https://ro.uow.edu.au/aiimpapers

Part of the Engineering Commons, and the Physical Sciences and Mathematics Commons

Research Online is the open access institutional repository for the University of Wollongong. For further information contact the UOW Library: research-pubs@uow.edu.au 


\title{
3D-Printed Conical Arrays of TiO2 Electrodes for Enhanced Photoelectrochemical Water Splitting
}

\author{
Abstract \\ Control over the topography of semiconducting materials can lead to enhanced performances in \\ photoelectrochemical related applications. One means of implementing this is through direct patterning \\ of metal-based substrates, though this is inadequately developed. Conventional techniques for patterned \\ fabrication commonly involve technologically demanding and tedious processes. 3D printing, a form of \\ additive fabrication, enables creation of a 3D object by deposition of successive layers of material via \\ computer control. In this work, the feasibility of fabricating metal-based 3D printed photoelectrodes is \\ explored. Electrodes comprised of conical arrays are fabricated and the performance for \\ photoelectrochemical water splitting is further enhanced by the direct growth of TiO2 nanotubes on this \\ platform. 3D metal printing provides a flexible and versatile approach for the design and fabrication of \\ novel electrode structures. \\ Disciplines \\ Engineering | Physical Sciences and Mathematics

\section{Publication Details} \\ Lee, C., Taylor, A. C., Beirne, S. \& Wallace, G. G. (2017). 3D-Printed Conical Arrays of TiO2 Electrodes for \\ Enhanced Photoelectrochemical Water Splitting. Advanced Energy Materials, 7 (21), \\ 1701060-1-1701060-6.
}




\section{WILEY-VCH}

DOI: $10.1002 /(($ please add manuscript number $))$

Article type: Communication

\section{D-Printed Conical Arrays of $\mathrm{TiO}_{2}$ Electrodes for Enhanced Photoelectrochemical Water Splitting}

Chong-Yong Lee*, Adam C. Taylor, Stephen Beirne, Gordon G. Wallace*

Dr. C.-Y. Lee, A. C. Taylor, Dr. S. Beirne, Prof. G. G. Wallace

ARC Centre of Excellence for Electromaterials Science,

Intelligent Polymer Research Institute,

AIIM, Innovation Campus,

University of Wollongong, Wollongong, NSW 2500, Australia.

E-mail: cylee@uow.edu.au,gwallace@uow.edu.au

Keywords: 3D printing, $\mathrm{TiO}_{2}$, water splitting, array electrodes, photoelectrochemistry

Clean, renewable and sustainable alternative energies are sought to replace the dwindling stocks of oil and natural gases. ${ }^{[1]}$ Fossil fuels emit environmentally detrimental and unwanted greenhouse gases such as carbon dioxide. In contrast, hydrogen is a clean-burning fuel that generates almost zero carbon emission with water and heat as products of combustion. ${ }^{[2]}$ The recent emergence of the hydrogen-economy in the transportation and power generation sectors highlight the potential of this alternative energy in transforming the way the world uses energy. ${ }^{[3]}$ However, the challenge remains on the efficient generation of clean and renewable hydrogen, as well as its storage and transportation. For the former, electrochemical and photoelectrochemical (PEC) water splitting are among the most investigated and promising approaches to generate renewable hydrogen. ${ }^{[1 \mathrm{a}, 4-5]}$

The landmark discovery by Honda and Fujishima in 1972 used $\mathrm{TiO}_{2}$ to split water to produce $\mathrm{H}_{2}$ under UV-Visible illumination. ${ }^{[6]}$ Since then, significant progress has been achieved on semiconductor based photocatalytic and PEC water splitting systems. The greater fundamental understanding of semiconductors, the discovery of new semiconductors, along with approaches such as band-gap engineerings and surface modifications have been instrumental towards improving photo(-electro)catalytic water splitting performance. ${ }^{[5]}$ 


\section{WILEY-VCH}

Particularly, nanostructuring efforts towards formation of low-dimensional nanomaterials (such as nanosheets, nanotubes, nanorods and nanoparticles) have led to morphology with improved surface area, light absorption and photoelectric functional properties, offering significant advantages in comparison to their bulk properties. ${ }^{[7]}$

Patterning of semiconducting materials with desirable texture and architecture is one of the effective approaches to enhance photocatalytic performance. ${ }^{[8-9]}$ Techniques such as femtosecond laser pulses, ${ }^{[10]}$ excimer laser irradiation, ${ }^{[11]}$ top-down contact lithography, ${ }^{[12]}$ template-assisted atomic layer deposition $(\mathrm{ALD})^{[13-14]}$ and micro-contact printing ${ }^{[9]}$ have been employed to pattern $\mathrm{TiO}_{2}$ thin films on various substrates. However, patterning direct on metal-based substrates is less explored, as it commonly involves technological demanding and tedious processes. Due to titanium's very high Young' modulus (116 GPa), nanoimprinting on titanium substrates has been rarely reported, ${ }^{[15]}$ in comparison to soft metals such as aluminium. ${ }^{[16-17]}$ Focused ion beam (FIB) lithography, on the other hand, allows nanopatterning of $\mathrm{Ti}$ in the range of tens of nanometres in a highly precise and direct manner into a titanium substrate, however, this is a slow and sequential technique that is hard to scale up to large substrates. ${ }^{[18-19]}$

The growing applications of 3D printing, known as an additive manufacturing, provides an attractive approach to synthesize a 3D object that is formed via the deposition of successive layers of material via computer control. ${ }^{[20-21]}$ While additive manufacturing has been embraced by industries such as aerospace engineering and medical orthopedics, ${ }^{[20]}$ metal-based 3D printing has recently been extended for fabricating electrode materials for applications such as micro-supercapacitors, ${ }^{[22]}$ microfluidic chips/cells ${ }^{[23]}$ and sensors ${ }^{[24]}$. Other printing approaches have also been advocated for electrochemical applications. ${ }^{[25]}$ However, to the best of our knowledge, there is no report on the use of 3D metal-based printing to form photoelectrodes. In this communication, we explore the prospect of 


\section{WILEY-VCH}

fabricating metal-based 3D printed photoelectrodes. The advantages and current limitations of this technology for the production of such photoelectrodes are evaluated and discussed.
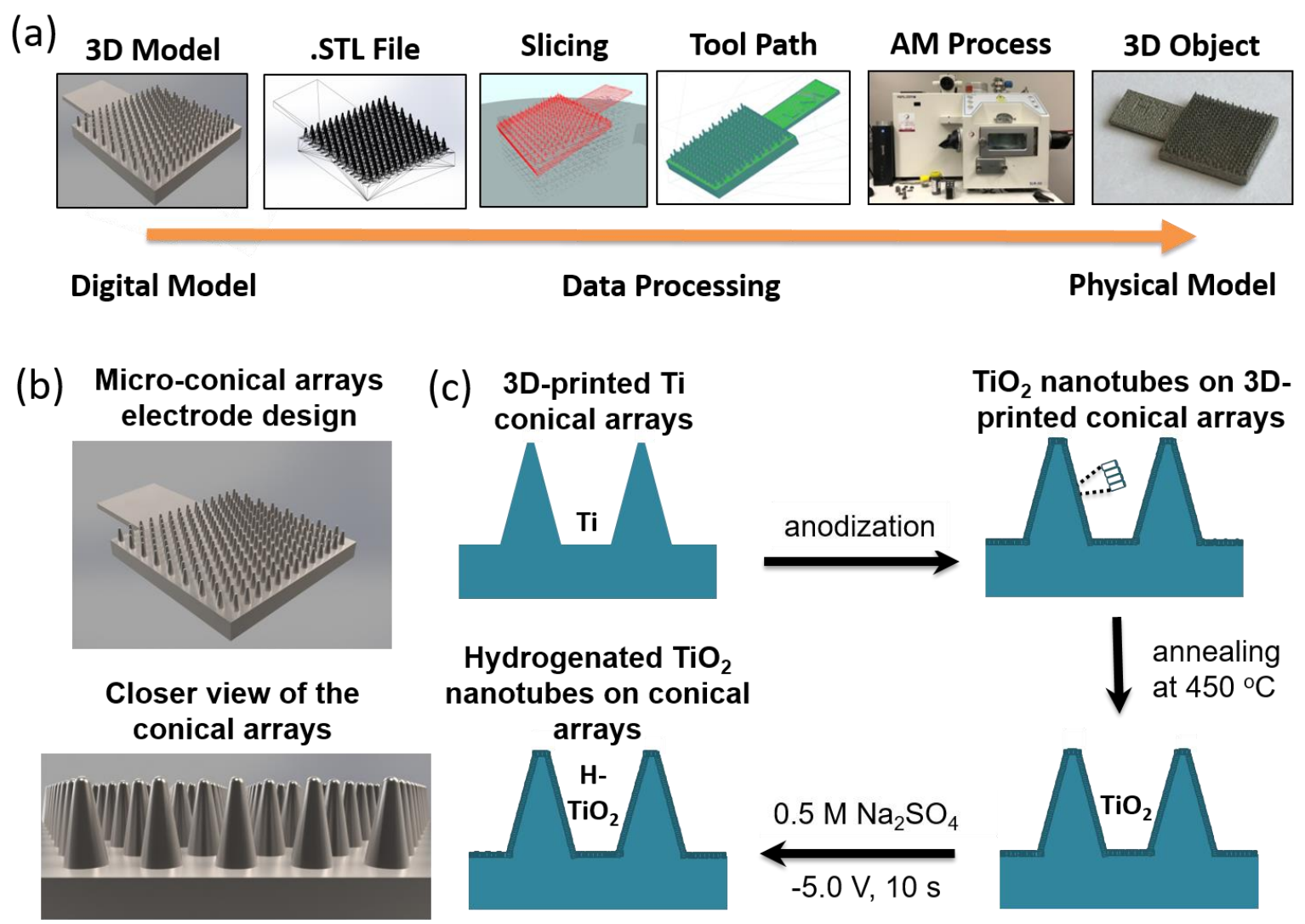

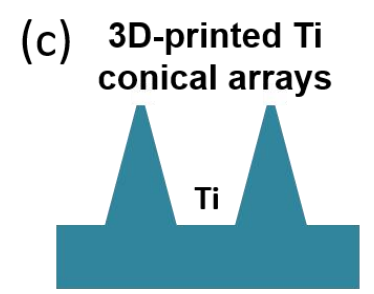

Hydrogenated $\mathrm{TiO}_{2}$
nanotubes on conical

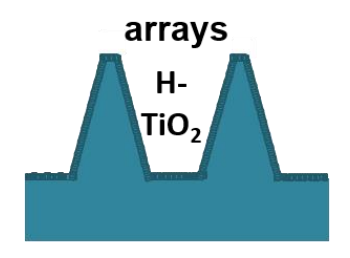

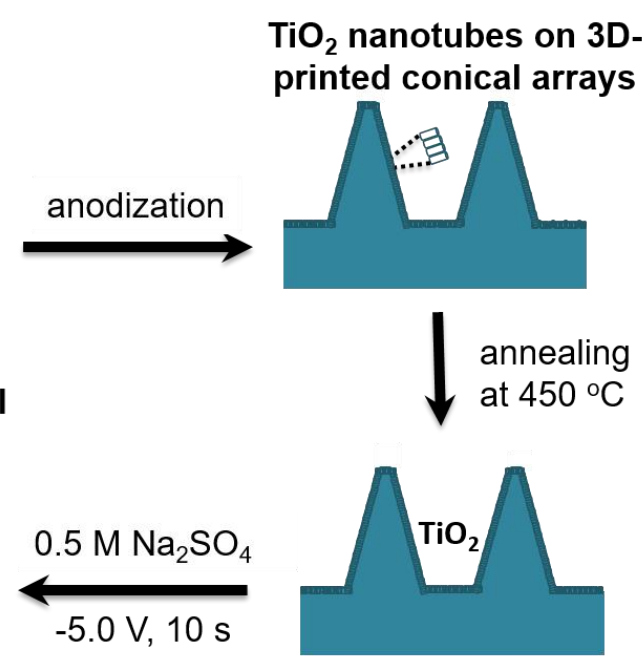

Figure 1 (a) Schematic illustration of the procedure to fabricate 3D printed electrodes from the software modelling to the printing of structures by using SLM machine. (b) Graphical illustrations of the fabricated conical-arrays microstructures with overview and closer look at the conical features images. (c) Schematic illustration of the steps taken to produce enhanced functionality hydrogenated $1 \mathrm{D}$ nanotubular structures of $\mathrm{TiO}_{2}\left(\mathrm{H}-\mathrm{TiO}_{2}\right)$ onto $3 \mathrm{D}$ printed conical arrays microstructures.

We employed the additive manufacturing technique for metal printing based using Selective Laser Melting (SLM) technology to produce 3D titanium based electrodes with a tuneable and printable microstructure of conical arrays. SLM utilises a high-powered laser to sequentially weld cross-sectional areas of a designed component, allowing for the creation of 


\section{WILEY-VCH}

intricate and complex geometries from a metal powder. This laser beam injects sufficient heat into the powder to allow the material to reach its melting temperature and subsequently, fuse the particles together. While a wide range of materials can be processed via this technique, the most common powders in SLM systems include varieties of steel, titanium, aluminium, nickel, as well as bronze or precious-metal-based alloys. As shown in Figure 1a, computeraided design (CAD) software was utilized to create the desired model of a 3D structure; this was then converted to the required file format, .STL (standard tessellation language) for further processing. This formatted data was sliced into layers, creating a cross-section for each layer. The sliced digital model was then further processed; assigning relevant laser parameters to fuse Ti powder (Grade 2) as well as a designed sacrificial support structure to allow the electrodes to build without any heat distortion and at optimal resolution. Finally, this is then executed by the selected additive manufacturing technique, SLM, depositing and melting the powder, layer-by-layer, until the physical model has been produced.

Efficient photoelectrochemical water splitting demands a high surface area photoelectrode with enhanced light absorption and charge separation. Taking advantage of the ease of design and fabrication of metal-based electrodes by 3D printing technology, we printed Ti-based electrodes of conical-arrays microstructures (Figure 1b). Conical structures may provide the advantage of light absorption and enhanced surface area, as such nanoscale structures have been proven to be beneficial for the Si-based solar cell applications. ${ }^{[26-27]}$ The system used, a Realizer SLM50, offers a z-resolution of $25 \mu \mathrm{m}$ and a minimum feature size of approximately $130-150 \mu \mathrm{m}$, though the feature size may vary dependent upon the surrounding structure and powder size (25 - $60 \mu \mathrm{m}$ spherical particles). The micron-ranged features which can be created using this 3D printing process make it ideal for producing small electrodes; it is possible to customise the surface area by creating structures on the electrodes surface. As such, we can tune an electrodes surface area by creating different sized cones, and 


\section{WILEY-VCH}

utilising different patterning densities, thereby increasing the apparent reactive area for the electrode.

To reach a reliable feature size, conical structures were tessellated across a titanium base measuring $1 \mathrm{~cm}^{2}$. To produce this design with the highest level of accuracy, the electrodes were printed at a small angle of inclination to reduce any distortion and minimise the internal stresses from the fabrication process (Figure S1), ensuring the electrodes were produced as flat as possible without comprimising on repeatability. The electrodes were subsequently removed from the build tray and all excess support material removed. Simultaneously, flat electrodes were produced as controls. Table 1 summarized the variety of 3D-printed conical patterns designed onto a flat square electrode surface $\left(1 \mathrm{x} 1 \mathrm{~cm}^{2}\right)$; this topology would provide adequate angular features to increase apparent surface area as well as remain easy to produce via the selected form of additive fabrication. The experimental design involved producing cones with a combination of 2 different density patterns (see Table S1 and Figure S2). Each electrode was produced with a small contact tab for ease of electrical connection, these tabs were designed to be as small as practical for their purpose and to minimise any impact they may have on the electrode surface area (all electrodes had identical sized electrical tabs). This rationale design allowed for an apparent surface area (assuming smooth electrode surface) up to 3 times greater than a flat reference electrode. However, the irregular surfaces especially the particulate features on the 3D printed surface means the real active surface area is rather difficult to be determined precisely.

To enhance the functionality of the conical arrays structures, self-organized $\mathrm{TiO}_{2}$ nanotubes were formed directly onto those 3D printed Ti-based electrodes through electrochemical anodization. These nanoscale dimensions with a high aspect ratio of 1Dnanotubular structures not only enhanced the specific surface area, but are also expected to promote beneficial physical and electronic properties for photoelectrochemical water splitting. ${ }^{[7,17]}$ Figure 1c illustrates the procedure to functionalize the $3 \mathrm{D}$ printed Ti-based 


\section{WILEY-VCH}

conical array electrodes. Firstly, 1D nanotubular structures were formed on the conical array via anodization in $\mathrm{NH}_{4} \mathrm{~F}$ containing ethylene glycol-water electrolyte. This resulted in the creation of the unique 1D-nanostructure tubes onto the 3D micro-conical arrays architecture. This is followed by annealling the electrode at $450{ }^{\circ} \mathrm{C}$ for $1 \mathrm{~h}$; converting from the amorphous to crystaline $\mathrm{TiO}_{2}$. Further electrochemical reduction was performed to produce hydrogenated $\mathrm{TiO}_{2}$ nanotubes that improve their electrical conductivity, and enhance photoelectrochemical water splitting performance. ${ }^{[28-29]}$
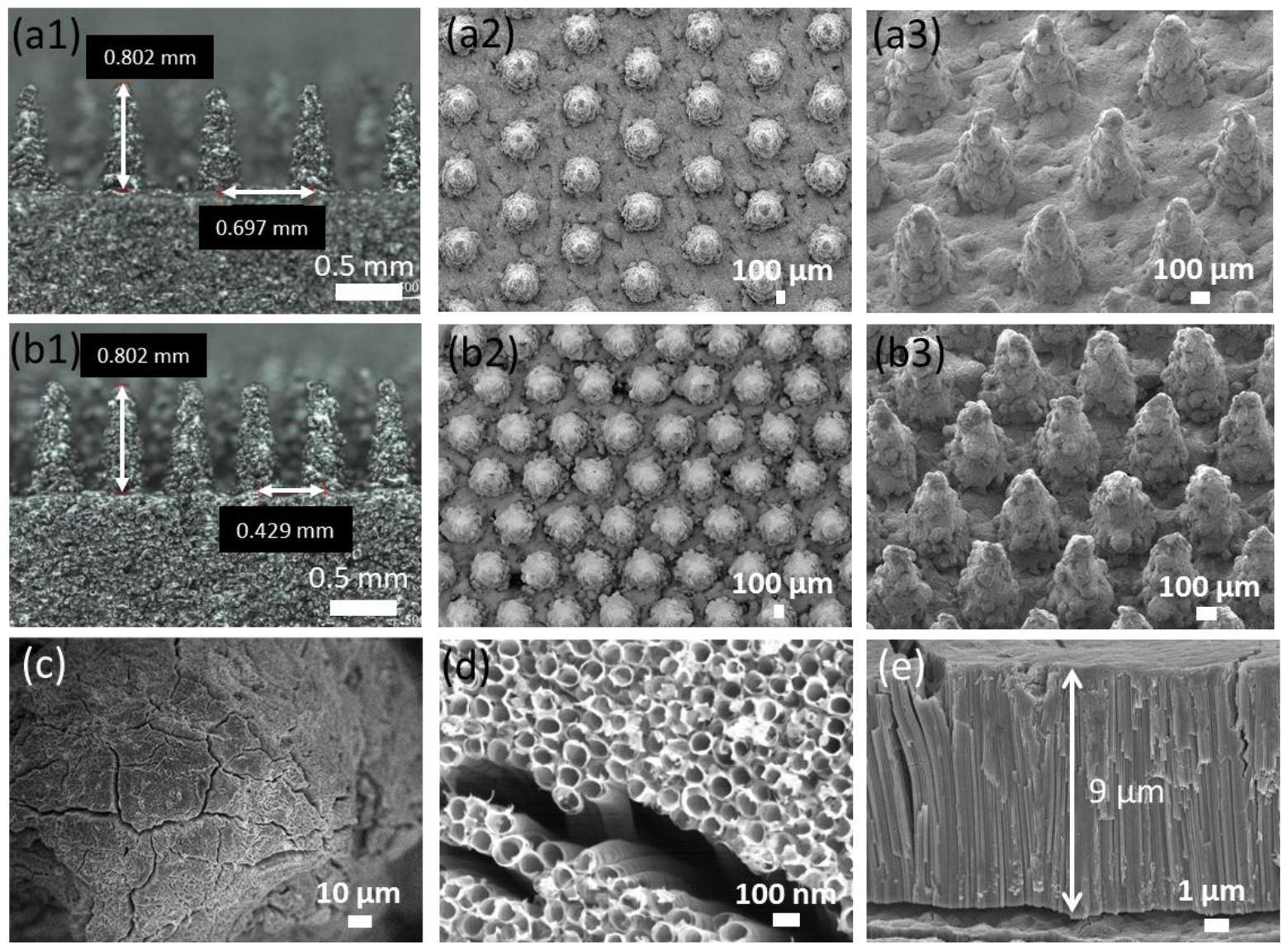

Figure 2 (a1) Side views optical images of printed conical arrays of Ti-based electrode consists of 216 cones (in $1 \mathrm{~cm}^{2}$ ) with distance between cones of $\sim 700 \mu \mathrm{m}$, (a2) and (a3) show the corresponding SEM images of anodized Ti-based electrode from the top and $30^{\circ}$ angled views, respectively. (b1) Side views optical images of printed conical arrays of Ti-based electrode consists of 407 cones (in $1 \mathrm{~cm}^{2}$ ) with distance between cones of $\sim 430 \mu \mathrm{m}$, (b2) and 


\section{WILEY-VCH}

(b3) show the corresponding SEM images of anodized Ti-based electrode from the top and angled views, respectively. SEM images of (c) the top view of the cone, (d) nanotubular structures and (e) the cross sectional thickness image of the form nanotubes.

Figure $2 \mathrm{a} 1-\mathrm{a} 3$ and $2 \mathrm{~b} 1-\mathrm{b} 3$ shows the optical and SEM images of the arrays electrodes which containing 216 (low density array) and 407 (high density array) cones, respectively. From the optical images (Figure 2a1 and 2b1), as a result of SLM printing process, it is apparent that a rough surface is obtained, from the base of electrode to the tip of the cones. Since the Grade 2 titanium employed consisted of particle sizes ranging from 25 to $60 \mu \mathrm{m}$, the tip of the cones exhibited tens of micron variations. Abrasive blasting is a method that can be employed to smooth this rough surface. However, considering further variations that may be introduced by the inhomogenous abrasive blast technique, we have used the as-formed 3D printed structures for the next anodization step. As can be seen in the SEM images of Figure 2a2-a3 and 2b2-b3, the anodized oxide layers consistently covered throughout the whole $\mathrm{Ti}$ surfaces. The SEM view (Figure 2c) of the top of the conical array shows the crack resulting from the growth of the amorphous $\mathrm{TiO}_{2}$ layer which consists of nanotubes (Figure $2 \mathrm{~d}$ ). The produced nanotube layer had a thickness of $\sim 9 \mu \mathrm{m}$. The average outer diameter of nanotubes is $\sim 110 \mathrm{~nm}$, with a tube wall thickness of $\sim 20 \mathrm{~nm}$ (Figure S3).

The electrodes which consist of as formed amorphous layers were annealed at $450{ }^{\circ} \mathrm{C}$ for $1 \mathrm{~h}$ for conversion to crystalline $\mathrm{TiO}_{2}$. The XRD patterns (Figure $3 \mathrm{a}$ ) of the crystalline as heated $\mathrm{TiO}_{2}$ and after electrochemical hydrogenation shows the peaks that can be indexed to anatase $\mathrm{TiO}_{2}$ (JCPDF no. 21-1272). No significant difference in the XRD phase is observed when comparing before and after electrochemical hydrogenation. As in agreement with the XRD data, the peaks from Raman spectra match well with the characteristic peaks of anatase at Raman shifts of $143\left(\mathrm{E}_{1 \mathrm{~g}}\right), 196\left(\mathrm{E}_{2 \mathrm{~g}}\right), 396\left(\mathrm{~B}_{1 \mathrm{~g}}\right), 514\left(\mathrm{~A}_{1 \mathrm{~g}}\right)$ and $638\left(\mathrm{E}_{3 \mathrm{~g}}\right) \mathrm{cm}^{-1}$. Importantly, a slight blueshift from 196.8 to $201.9 \mathrm{~cm}^{-1}$ (inset in Figure 3b) for hydrogenated sample 


\section{WILEY-VCH}

indicating the increased surface disorder due to the introduction of oxygen vacancies, as in agreement with other reports. ${ }^{[28-29]}$
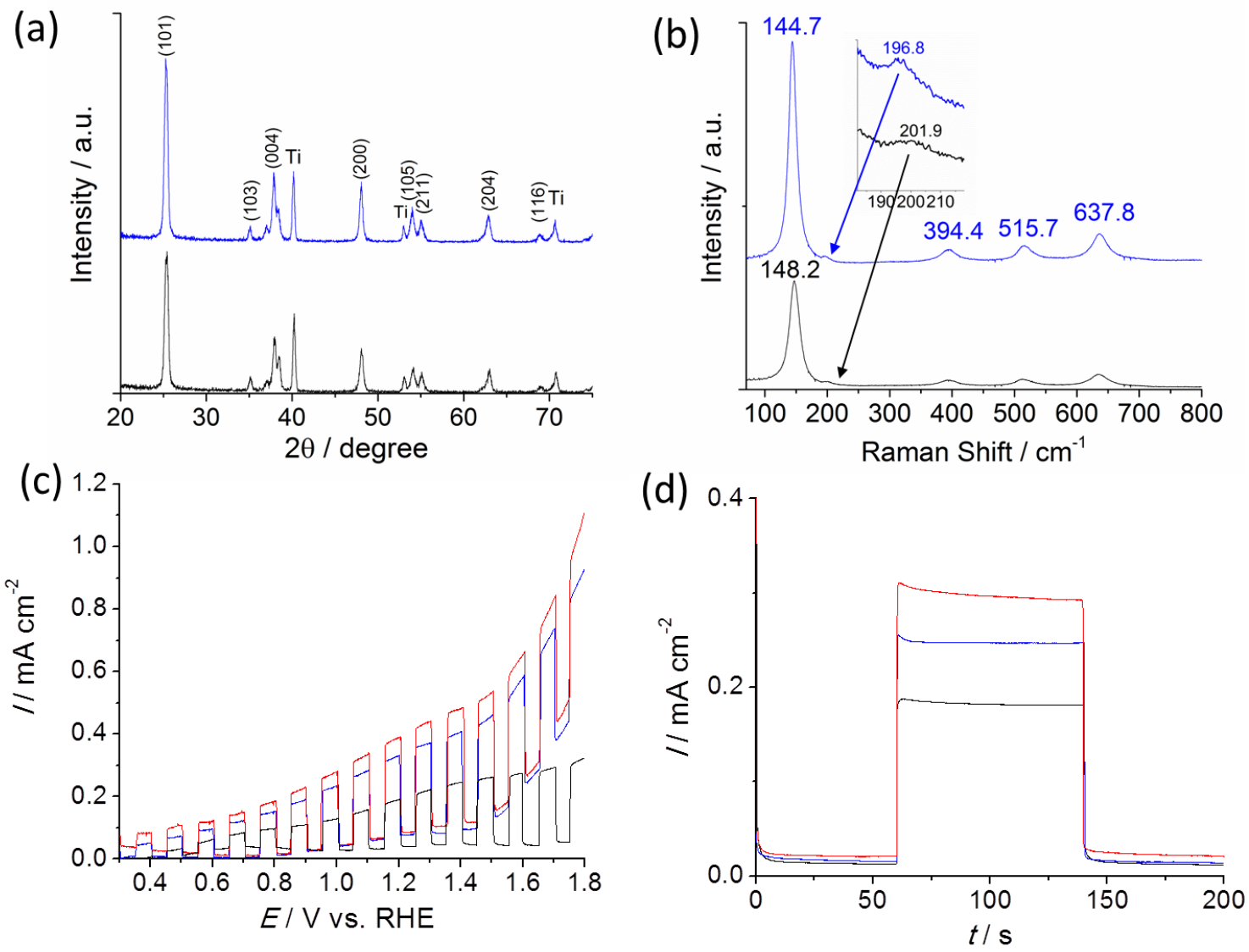

Figure 3 (a) XRD patterns of the $\mathrm{TiO}_{2}$ electrode heat-treated at $450{ }^{\circ} \mathrm{C}$ (blue), and after undergone electrochemical hydrogenation (black). (b) Raman spectra of the untreated $\mathrm{TiO}_{2}$ (blue) and hydrogenated $\mathrm{TiO}_{2}$ (black). (c) Chopped-light photoelectrochemical responses of $\mathrm{TiO}_{2}$ growth on the nominally flat substrate (black), in comparison to array electrodes consisting of 216 (blue) and 407 (red) cones. The corresponding current-time chopped photocurrent response at $1.2 \mathrm{~V}$ vs. RHE is shown in (d).

To evaluate the water splitting performance of the 3D-printed $\mathrm{TiO}_{2}$ array electrodes, we recorded current-voltage curves in $1 \mathrm{M} \mathrm{NaOH}$ solution using intermittant AM 1.5100 $\mathrm{mW} / \mathrm{cm}^{2}$ illumination. The nanotubes provide a porous oxide layer showing a significant 


\section{WILEY-VCH}

enhancement in photocurrent in comparison to the heat-treated bare Ti. The follow-up electrochemical hydrogenation by simple electrochemical reduction in $0.1 \mathrm{M} \mathrm{Na}_{2} \mathrm{SO}_{4}$ for $10 \mathrm{~s}$ is shown to be essential in promoting photoelectrochemical water splitting (Figure S4). Impedance spectroscopy studies performed in potassium ferricyanide solution show significantly low charge transfer resistance (the decrease in the Warburg resistance) for the electrode after hydrogenation has been performed (Figure S5). It is suggested that the increased surface disorder due to the introduction of oxygen vacancies is responsible for the improved conductivity and photoresponse as evidenced from our Raman spectra. ${ }^{[28-30]}$ To accurately compare the photoelectrochemical water splitting potential between the flat and conical electrodes, all structures were electrochemically hydrogenated.

Figure $3 \mathrm{c}$ shows a comparison of the current-potential chopped photoresponse of both nominally flat and conical array electrodes. A more consistent baseline of dark current is exhibited from the nominally flat electrode in comparison to the conical arrays, where the dark current starts from 1.0 V vs. RHE. This figure indicates a large increase in photoresponse across the applied potential when using the conical arrays in compare to nominally flat electrode. This trend also exists when comparing the low density and high density conical array electrodes, though the magnitude of increase in photoresponse decreased. For better illustration of the difference in the photoresponses, the chopped photoelectrochemical response was obtained at a potential of $1.2 \mathrm{~V}$ vs RHE. The result shows the trend of increasing photocurrent from the nominally flat, to low and high density conical arrays. This result indicates the role of conical features in improving surface area and enhanced light absorption, hence photoelectrochemical water splitting. However, it is likely that the irregularity in conical surface structure resulting from the additive fabrication process is affecting electrode performance, hence the photocurrents obtained do not directly correlate with the number of cones per electrode array. We further quantified the obtained products 


\section{WILEY-VCH}

from the photoelectrochemical water splitting experiment by a gas chromatography, which indicates $96 \pm 5 \%$ current conversion efficiency and the expected $\mathrm{H}_{2} / \mathrm{O}_{2}$ ratio of $\sim 2: 1$.

This work demonstrates the capability of additive fabrication to produce unique microstructure electrodes which have the ability to enhance reactive surface area and tune light absorption characteristics. The conical microarray structure produced via SLM technology compounded with the growth of nanotubes via anodization provides a distinctive blend of nano and microstructures that is beneficial for photoelectrochemical water splitting. We show the key advantages of $3 \mathrm{D}$ printing in the flexibility in designing tailor-made hierarchical metal-based photoelectrodes, for example in our work, micro-conical features of tunable size and density. Since they are conductive metal-based electrodes, further electrochemical treatments and surface modications can be readily performed to enhance their functionality. The major limitation of metal-based SLM for nanotechnology driven applications lies in the capability in creating features in micro- instead of nano- domain. We have however addressed to some extent this issue by introducing nanofeatures onto the hierarchical 3D microstructure. Furthermore, this method produces irregular microparticulate features on such microstructure instead of a smooth surface. This may limit the key beneficial features of photoelectrochemical performance obtained via nano- or sub-micron arrays with a smoother surface morphology achievable with methods such as ion beam induced deposition.

In conclusion, this work advocates the use of metal-based 3D printing to form a wide range of electrodes with unique architectures on various metal substrates for photoelectrochemical application. This is envisioned by further enhancement in 3D printing approaches, resolutions and capabilities, allowing advances in designing new generations of photoelectrodes. Combination of this metal-based 3D printing with other printing technologies may also allow the design of a complete 3D printable full photoelectrochemical water splitting device. 


\section{WILEY-VCH}

\section{Experimental Section}

\section{Materials and Chemicals:}

All materials and chemicals were used as received without further purifications. Deionized water (purified by a Mili-Q system) was used to prepare all solutions and to rinse samples and glassware.

3D Printing: 3D printed electrodes were first drawn using 3D modeling software. The electrodes were then built using Realizer SLM50 metal printer (Realizer, Germany). The Ti based electrodes was printed using a Grade $2 \mathrm{Ti}$ metal powder $(\mathrm{Fe} 0.03, \mathrm{O} 0.19, \mathrm{C} 0.02, \mathrm{~N}$ 0.04, H 0.005 wt \%, TLS TechnikSpezialpulver). The printed parts were removed from the build plate manually using a cutting process and underwent post-processing sonication in isopropyl alcohol (Sigma Aldrich) for 60 minutes. This sonication process would remove any loosely bound titanium particles, which may have adhered to the surface during the print process, but had not completely bonded to the component. The electrodes were sonicated with the array facing downwards to prevent any loose powder accumulation in the conical array. Samples were then dried using pressured nitrogen and anodised to initiate the growth of $\mathrm{TiO}_{2}$ nanotubes

Anodization: Anodization was performed in a solution of ethylene glycol (EG, Sigma Aldrich) containing 0.35 wt $\% \mathrm{NH}_{4} \mathrm{~F}$ (Sigma Aldrich) and 2 vol $\% \mathrm{H}_{2} \mathrm{O}$ at $60 \mathrm{~V}$ for $0.5 \mathrm{~h}$. After anodization, the samples were rinsed with water and ethanol, followed by drying in nitrogen. The obtained amorphous samples were then heat-treated in air (Programmer, PR 53T) for $1 \mathrm{~h}$ at $450^{\circ} \mathrm{C}$.

Photoelectrochemical water splitting experiments: All photoelectrochemical water splitting measurements were performed in a three-electrode configuration using an $\mathrm{Ag} / \mathrm{AgCl}(3 \mathrm{M}$ 


\section{WILEY-VCH}

$\mathrm{NaCl}, \mathrm{BASi}$ ) electrode as a reference electrode, platinum foil as a counter electrode and the 3D-printed Ti-based electrode as a photoanode, connected to a potentiostat $(\mathrm{CH}$ Instrument 650D). The measurements were performed in a $\mathrm{H}$-shape cell in $1.0 \mathrm{M} \mathrm{NaOH}$ (Sima-Aldrich) and the potential value was converted to a RHE scale using the relationship $E_{\mathrm{RHE}}=E_{\mathrm{Ag} / \mathrm{AgCl}}+$ $0.0591 \times p H+0.1976 \mathrm{~V}$. The samples were illuminated under AM 1.5 solar simulator where the light intensity was calibrated to be $100 \mathrm{~mW} \mathrm{~cm}^{-2}$ using a calibrated silicon detector. Photocurrent transients as a function of the applied potential were recorded by chopped-light irradiation (60 s in the dark and $80 \mathrm{~s}$ in the light).

Characterization: The electrodes were analysed by X-ray diffraction (XRD, GBC MMA diffractometer) with $\mathrm{Cu} \mathrm{K} \alpha$ radiation at a scan rate of 2 degree per min. The morphology of the samples was investigated by field emission scanning electron microscopy (FESEM, JEOL JSM-7500FA). The resulting electrodes were imaged using a Leica M205 optical microscope and the associated dimensions compared to the CAD counterparts for physical reference. Raman Spectra were recorded on a Jobin Yvon Horiba HR800 Raman microscope using a $632 \mathrm{~nm}$ laser line. Impedance spectroscopy was performed using a potentiostat $(\mathrm{CH}$ Instrument 650D).

Product Quantification: The gaseous products were quantified by headspace gas analysis using a gas chromatograph (8610C, SRI Instruments) with a packed $5 \AA$ molecular sieve column, a packed Haysep D column and a thermal conductivity detector. Argon was used as the carrier gas. The electrochemical cell was purged with Argon for at least 15 min prior to experiment. $\approx 40 \mu \mathrm{L}$ aliquots of headspace gas were removed using a gas-tight syringe (SGE).

\section{Supporting Information}

Supporting Information is available from the Wiley Online Library or from the author. 


\section{WILEY-VCH}

\section{Acknowledgements}

This work was supported by the University of Wollongong's Vice Chancellor Research Fellowship (to CYL). Funding from the Australian Research Council Centre of Excellence Scheme (CE 140100012) is gratefully acknowledged. We thank Dr. Patricia Hayes for her help in Raman Spectroscopy experiment. The authors would also like to thank Australian National Fabrication Facility-Materials Node (ANFF) and UOW Electron Microscopy Centre for equipment use.

Received: ((will be filled in by the editorial staff))

Revised: ((will be filled in by the editorial staff)) Published online: ((will be filled in by the editorial staff))

\section{References}

[1] a) M. G. Walter, E.L. Warren, J. R. McKone, S. W. Boettcher, E. A. Santori, N. S. Lewis, Chem. Rev., 2010, 110, 6446 ; b) N. N. Armaroli, V. Balzani, Energy for a Sustainable World,Wiley-VCH, Weinheim, Germany, 2011.

[2] J. O’M. Bockris, Int. J. Hydrogen Energy 2002, 27, 731.

[3] A. Züttel, A. Borgschulte, L. Schlapbach, Hydrogen as a Future Energy Carrier, WileyVCH: Weinheim, Germany, 2008.

[4] a) H. Schäfer, D. M. Chevrier, P. Zhang, J. Stangl, K. Müller-Buschbaum, J. D. Hardege, K. Kuepper, J. Wollschläger, U. Krupp, S. Dühnen, M. Steinhart, L. Walder, S. Sadaf, M. Schmidt, Adv. Funct. Mater. 2016, 26, 6402; b) F. Le Formal, W. S. Bourée, M. S. Prévot, K. Sivula, Chimia, 2015, 69, 789; c) H. Schäfer, D. M. Chevrier, K Kuepper, P Zhang, J Wollschlaeger, D. Daum, M. Steinhart, C. Heß, U. Krupp, K. Müller-Buschbaum, J. Stangl, M. Schmidt, Energy Environ. Sci., 2016, 9, 2609; d) H. Schäfer, S. M. Beladi-Mousavi, L. Walder, J. Wollschläger, O. Kuschel, S. Ichilmann, S. Sadaf, M. Steinhart, K. Küpper, L. Schneider, ACS Catal., 2015, 5, 2671; e) D. Tang, O. Mabayoje, Y. Lai, Y. Liu, C. B. Mullins, ChemistrySelect, 2017, 2, 2230; f) F. Yu, F. Li, L. Sun, Int. J. Hydrogen Energy, 2016, 41, 5230.

[5] a) A. Kudo, Y. Miseki, Chem. Soc. Rev. 2009, 38, 253; b) Z. S. Li, W. J. Luo, M. L. Zhang, J. Y. Feng, Z. G. Zou, Energy Environ. Sci., 2013, 6, 347; c) X. Chen, S. Shen, L. Guo, S. S. Mao, Chem. Rev. 2010, 110, 6503; d) T. Hisatomi, J. Kubota, K. Domen, Chem. Soc. Rev., 2014, 43, 7520; e) H. Kato, A. Kudo, J. Phys. Chem. B 2002, 106, 5029.

[6] A. Fujishima, H. Honda, Nature, 1972, 238, 37.

[7] a) Govindaraj, A. and Rao, C.N.R. (2005) The Chemistry of Nanomaterials, Wiley-VCH Verlag GmbH \& Co. KGaA, pp. 208-284; b) Weisbuch, C. and Vinter, B. (1991), Quantum Semiconductor Structures: Fundamentals and Applications, Elsevier, Amsterdam; c) K. Lee, A. Mazare, P. Schmuki, Chem. Rev., 2014, 114, 9385; d) C.-Y. Lee, L. Wang, Y. Kado, M. S. Killian, P. Schmuki, ChemSusChem, 2014, 7, 934; e) Y. Kado, R. Hahn, C.-Y. Lee, P. Schmuki, Electrochem. Commun. 2012, 17, 67-70; f) C.-Y. Lee, L. Wang, Y. Kado, R. Kirchgeorg, P. Schmuki, Electrochem. Commun. 2013, 34, 308.

[8] D. V. Esposito, Y. Lee, H. Yoon, P. M. Haney, N. Y. Labrador, T. P. Moffat, A. A. Talin, V. A. Szalai, Sustainable Energy Fuels, 2017, 1, 154

[9] D. Chen, Y. Gao, G. Wang, H. Zhang, W. Lu, J. Li, J. Phys. Chem. C., 2007, 111, 13163. [10] S. Passinger, M. S. Saifullah, C. Reinhardt, K. R. V. Subramanian, B. N. Chichkov, M. E. Welland, Adv. Mater. 2007, 19, 1218.

[11] A. Narazaki, Y. Kawaguchi, H. Niino, M. Shojiya, H. Koyo, K. Tsunetomo, Chem. Mater. 2005, 17, 6651.

[12] L. Francioso, P. Siciliano, Nanotechnology, 2006, 17, 3761. 


\section{WILEY-VCH}

[13] X. D. Wang, E. Graugnard, J. S King, Z. L. Wang, C. J. Summers, Nano Lett. 2004, 4, 2223.

[14] S. M. George, Chem. Rev. 2010, 110, 111.

[15] a) J. Choi, R. B Wehrspohn, J. Lee, U. Gösele, Electrochim. Acta, 2004, 49, 2645. b)T.

Kondo, S. Nagao, T. Yanagishita, N. T. Nguyen, K. Lee, P. Schmuki, H. Masuda,

Electrochem. Commun. 2015, 50, 73.

[16] a) W. Lee; R. Ji; C. A. Ross, U. Gösele, K. Nielsch, Small, 2006, 2, 978; b) H. Masuda,

H. Yamada, M. Satoh, H. Asoh, M. Nakao, T. Tamarura, Appl. Phys. Lett. 1997, 71, 2770; c)

H. Masuda, H. Asoh, M. Watanabe, K. Nishio, M. Nakao, T. Tamamura, Adv. Mater. 2001, $13,189$.

[17] C.-Y. Lee and P. Schmuki, in Advances in Electrochemical Sciences and Engineering book series, Volume 15 (Eds: R.C. Alkire, P. N. Bartlett and J. Lipkowski), Wiley-VCH, Weinheim, Germany, 2015, Ch. 5.

[18] B. Chen, K. Lu, Langmuir, 2011, 27, 12179.

[19] B. Chen, K. Lu, J. A. Geldmeier, Chem. Commun. 2011, 47,10085.

[20] A. Gebhardt, Understanding additive manufacturing: rapid prototyping, rapid tooling, rapid manufacturing, Cincinnati: Hanser Publishers, Munich, 2012.

[21] C. Barnatt, $3 D$ printing: the next industrial revolution, $2^{\text {nd }}$ Edition, CreateSpace Independent Publishing Platform, 2014.

[22] C. Zhao, C. Wang, R. Gorkin III, S. Beirne, K. Shu, G. G.Wallace, Electrochem. Commun., 2014, 41, 20.

[23] A. K. Au, W. Huynh, L. F. Horowitz, A. Folch, Angew. Chem. Int. Ed. 2016, 55, 3862.

[24] A. Ambrosi, J. G. S. Moo, M. Pumera, Adv. Funct. Mater., 2016, 26, 698.

[25] A. Ambrosi, M. Pumera, Chem. Soc. Rev., 2016, 45, 2740.

[26] Y. Lu, A. Lal, Nano Lett., 2010, 10, 4651.

[27] S. Jeong, E. C. Garnett, S. Wang, Z. Yu, S. Fan, M. L. Brongersma, M. D. McGehee, Y. Cui, Nano Lett., 2012, 12, 2971.

[28] C. Xu, Y. Song, L. Lu, C. Cheng, D. Liu, X. Fang, X. Chen, X. Zhu, D. Li, Nanoscale Res. Lett. 2013, 8:391.

[29] X. Chen, L. Liu, P. Y. Yu, S. S. Mao, Science, 2011, 331, 746.

[30] A. Naldoni, M. Allieta, S. Santangelo, M. Marelli, F. Fabbri, S. Cappelli, C.L. Bianchi, R. Psaro, V. Dal Santo, J. Am. Chem. Soc. 2012, 134, 7600. 


\section{WILEY-VCH}

Advanced 3D-printed conical arrays of Ti-substrates are acting as substrates to form $\mathrm{TiO}_{2}$ based photoanodes with enhanced photoelectrochemical water splitting performance. Tunable sizes and densities of conical arrays are achievable from 3D printing technology. This 3D printed metal-based structures in addition to ease of functional modifications opening a new way in fabricating novel electrode materials for photoelectrochemical related applications.
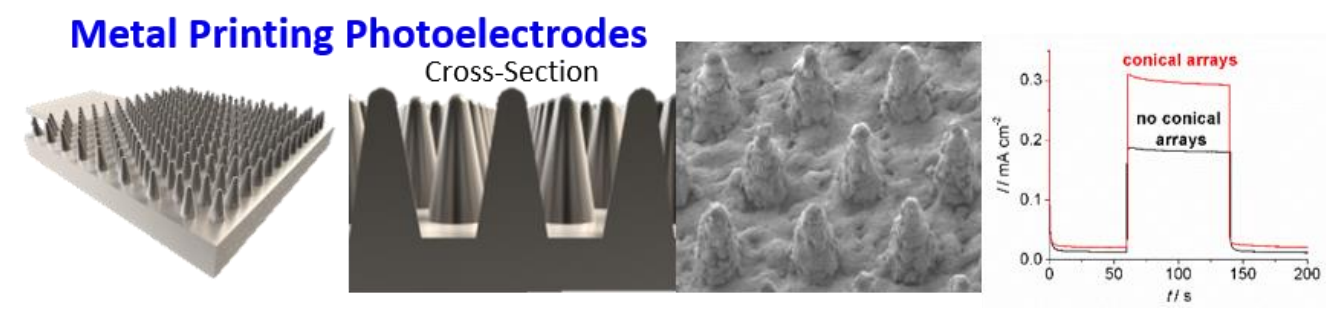

\section{Keyword}

3D-printing, $\mathrm{TiO}_{2}$, Water splitting, Conical Arrays, Photoelectrochemistry

Chong-Yong Lee*, Adam C. Taylor, Stephen Beirne, Gordon G Wallace*

3D-Printed Conical Arrays of $\mathrm{TiO}_{2}$ Electrodes for Enhanced Photoelectrochemical Water Splitting 


\section{WILEY-VCH}

Copyright WILEY-VCH Verlag GmbH \& Co. KGaA, 69469 Weinheim, Germany, 2016.

\section{Supporting Information}

3D-Printed Conical Arrays of $\mathrm{TiO}_{2}$ Electrodes for Enhanced Photoelectrochemical Water Splitting

Chong-Yong Lee, Adam C. Taylor, Stephen Beirne and Gordon G. Wallace

ARC Centre of Excellence for Electromaterials Science,

Intelligent Polymer Research Institute, AIIM,

Innovation Campus,

University of Wollongong, Wollongong,

NSW 2500, Australia.

E-mails: cylee@uow.edu.au,gwallace@uow.edu.au 


\section{WILEY-VCH}

Table S1 The comparison of the cone height, spacing, number, and total surface area for the flat surface in comparison to arrays of cones with medium and high densities levels.

\begin{tabular}{ccccc}
\hline Arrays of cones & $\begin{array}{c}\text { Cone height } \\
{[\mu \mathrm{m}]}\end{array}$ & $\begin{array}{c}\text { Cone spacing } \\
{[\mu \mathrm{m}]}\end{array}$ & $\begin{array}{c}\text { Number of } \\
\text { cone }\end{array}$ & $\begin{array}{c}\text { Total surface } \\
\text { area }^{\mathrm{b}} \\
{\left[\mathrm{cm}^{2}\right]}\end{array}$ \\
\hline None & 0 & 0 & 0 & 1.00 \\
Medium density & 814 & 500 & 216 & 2.197 \\
High density & 814 & 700 & 407 & 3.256
\end{tabular}

acone base diameter:- $400 \mu \mathrm{m}$; cone tip diameter:-150 $\mu \mathrm{m}$; each cone area $=0.12566$

$\mathrm{mm}^{2}$, bassuming the smooth electrode surface, whereas in reality the printed electrodes show apparent surface irregularity. 


\section{WILEY-VCH}

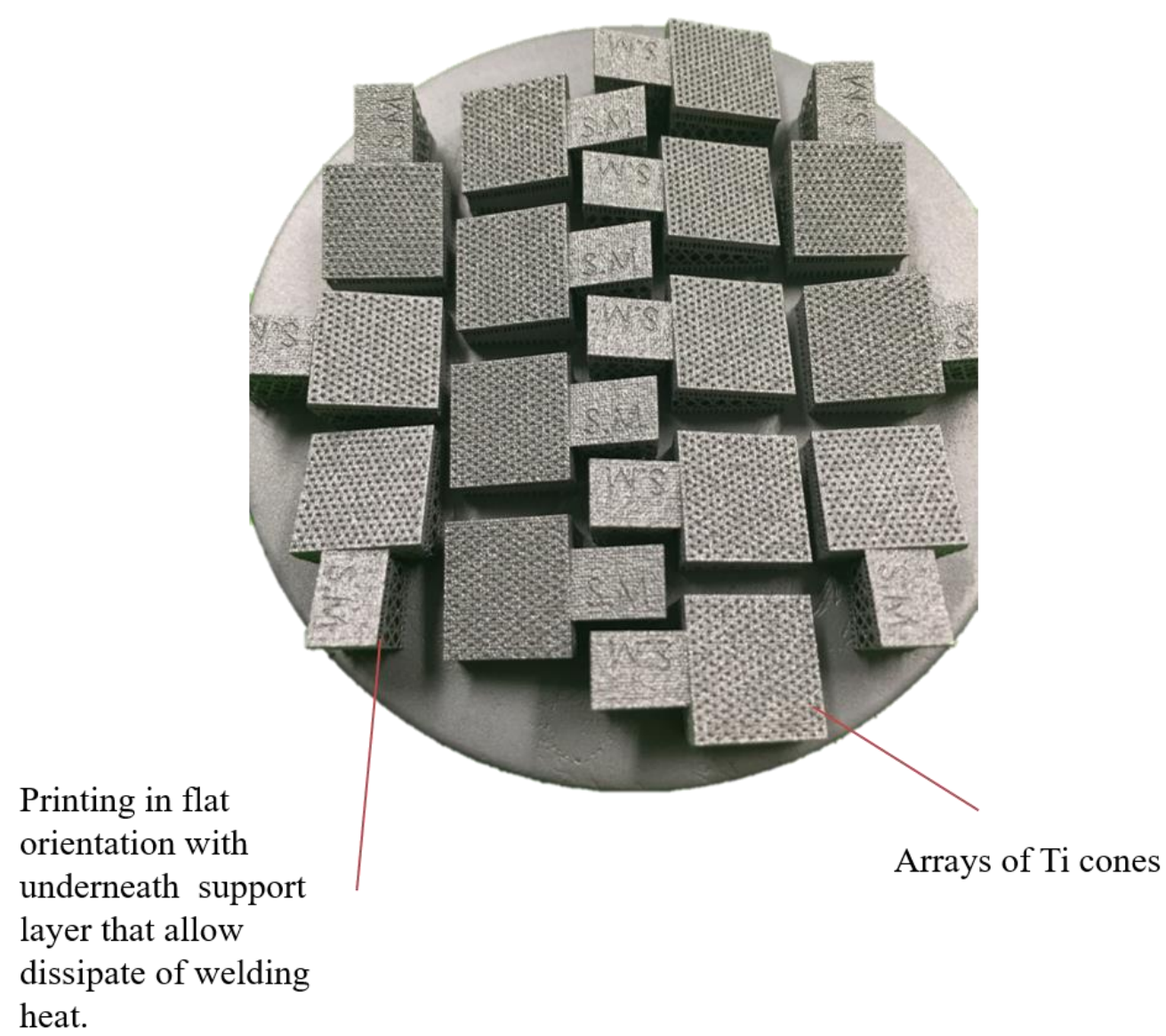

Figure S1 An optical image showing a tray of 3D-printed electrodes fabricated in a flat orientation with underneath support layer allowing heat dissipation. 


\section{WILEY-VCH}

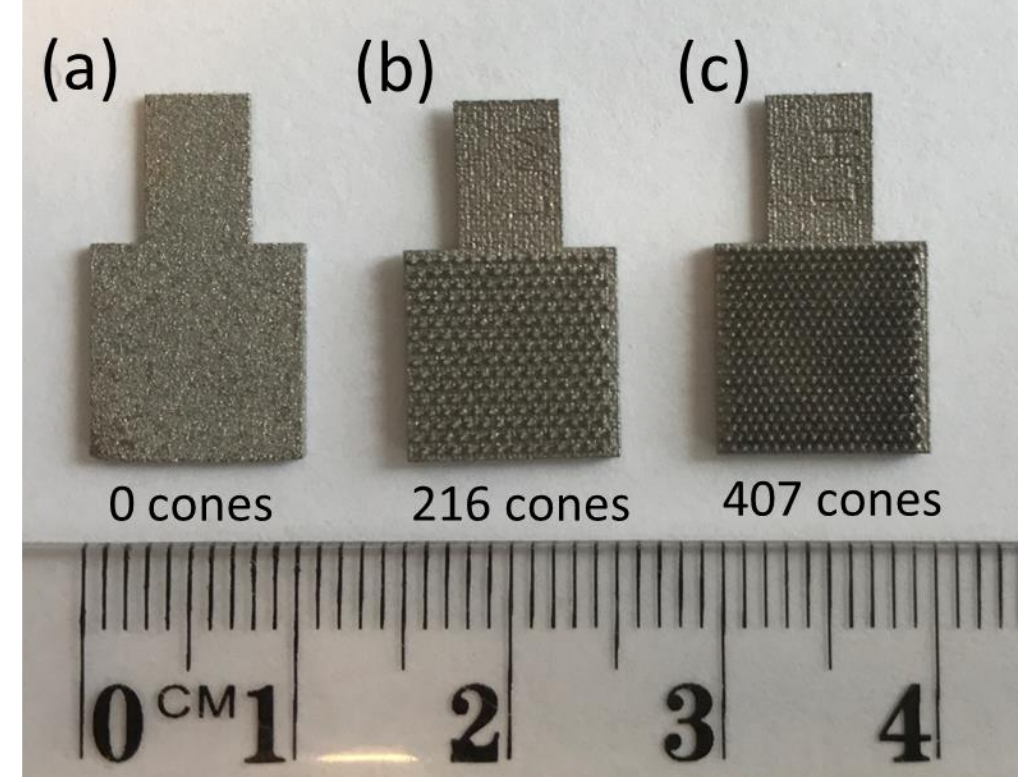

Figure S2 Optical images of 3D printed electrodes of (a) nominally flat electrode with 0 cone, and conical arrays electrodes consisting of (b) 216 and (c) 407 cones, respectively. 


\section{WILEY-VCH}
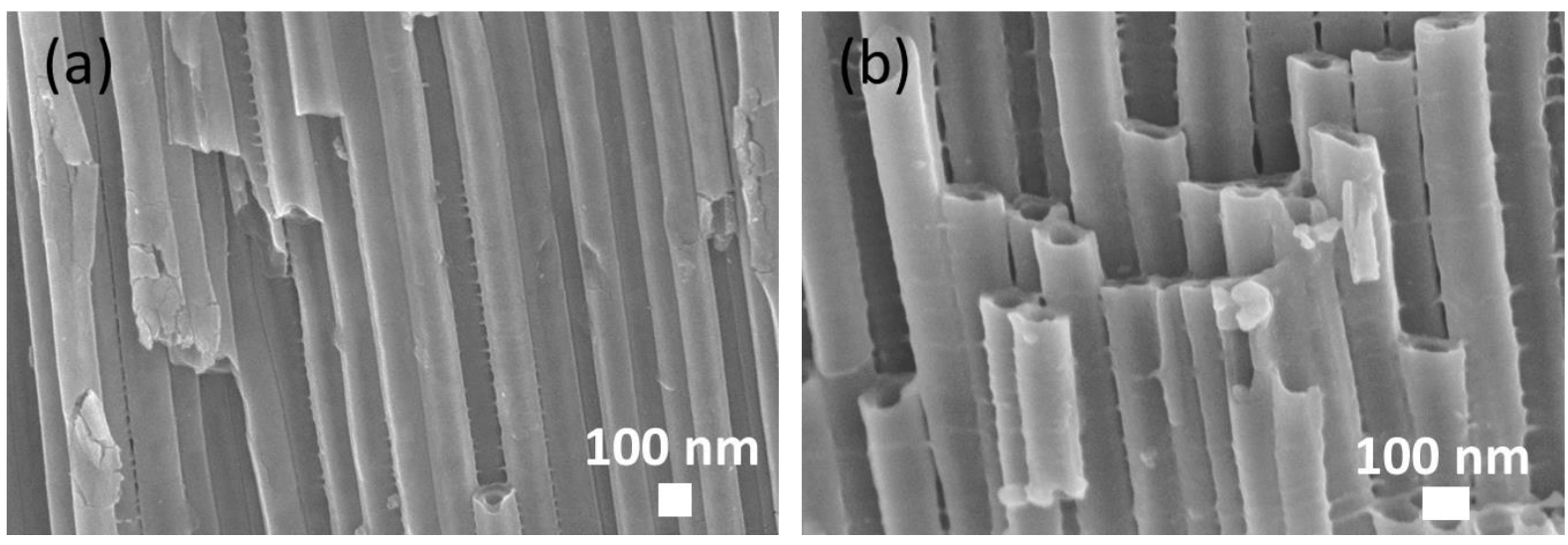

Figure S3 The side view of SEM image of the formed $\mathrm{TiO}_{2}$ nanotubes, (a) with an average tube outer diameters of $\sim 110 \mathrm{~nm}$, (b) walls of with thicknesses of $\sim 20 \mathrm{~nm}$. 


\section{WILEY-VCH}

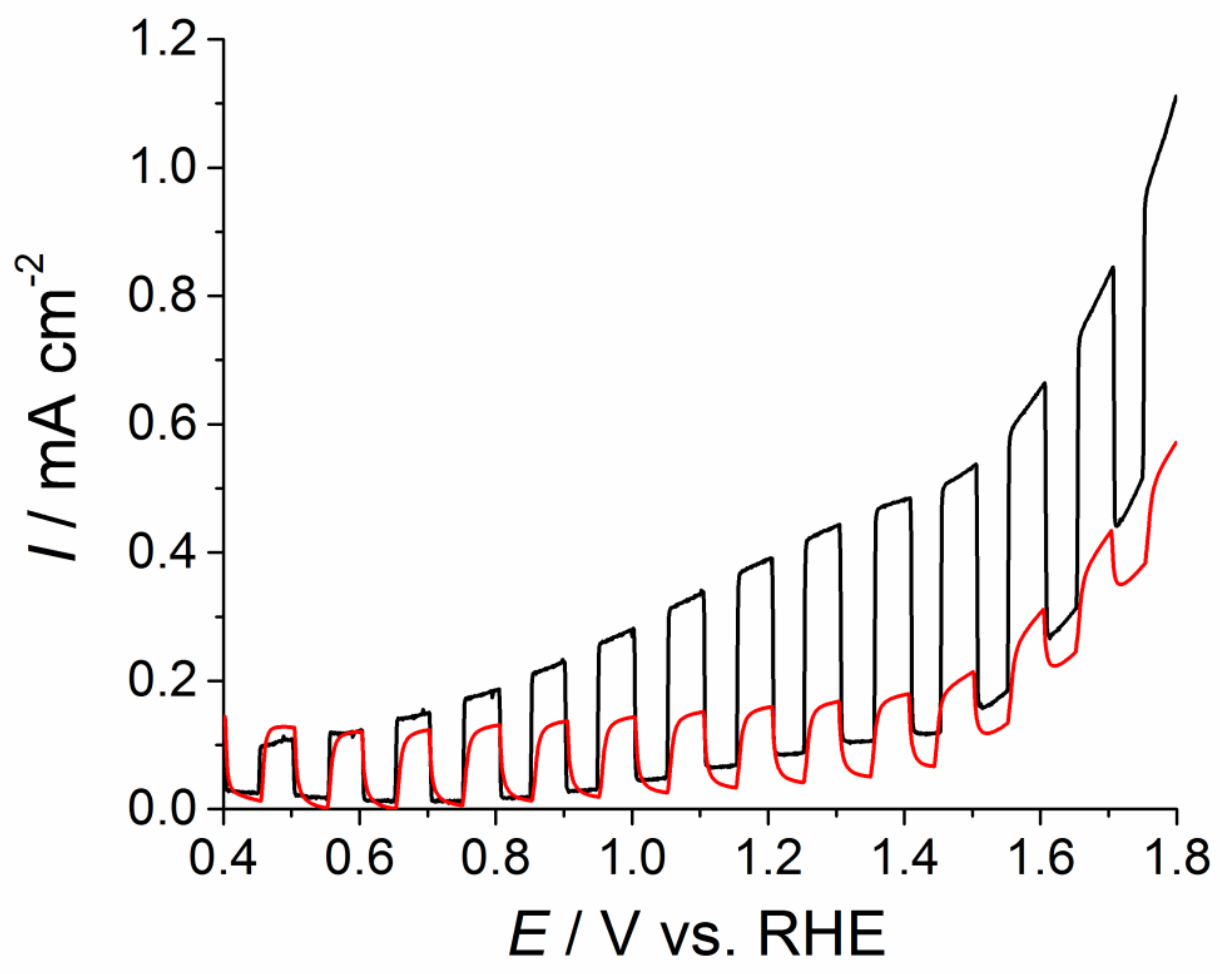

Figure S4 Chopped-light photoelectrochemical responses of the 407 cones arrays $\mathrm{TiO}_{2}$ electrode that heat-treated at $450 \mathrm{oC}$ for $1 \mathrm{~h}$, before (red) and after (black) undergone electrochemical hydrogenation. 


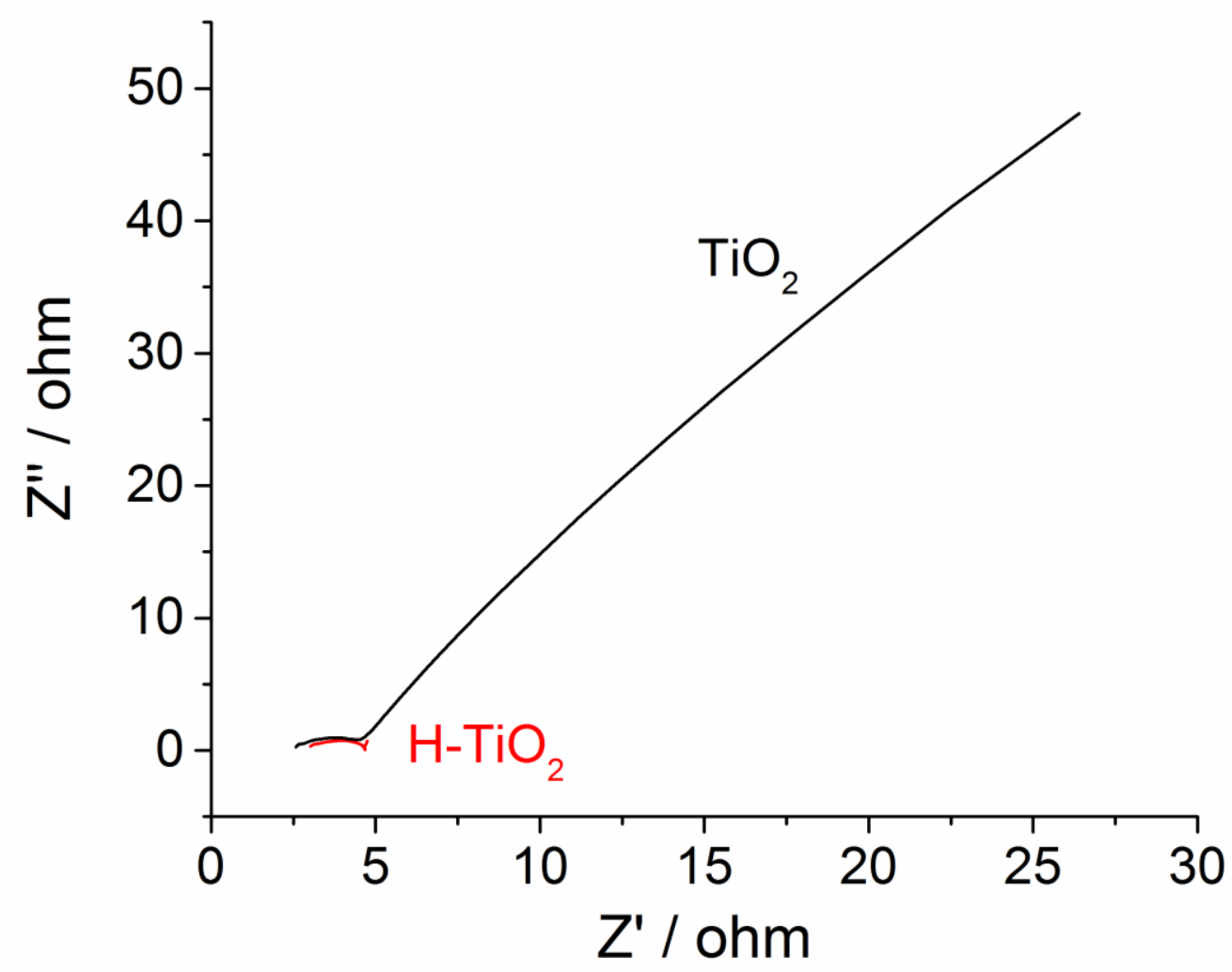

Figure S5 Comparison of Nyquist plots of $\mathrm{TiO}_{2}$ and hydrogenated $\mathrm{TiO}_{2}$ electrodes $\left(\mathrm{H}-\mathrm{TiO}_{2}\right)$ performed in $1 \mathrm{mM}$ potassium ferricyanide containing $0.5 \mathrm{M} \mathrm{KCl}$. 